\title{
Identification of potential biomarkers for abdominal pain in IBS patients by bioinformatics approach
}

\author{
Zhongyuan Lin ${ }^{1 \dagger}$, Yimin Wang ${ }^{2 \dagger}$, Shiqing Lin ${ }^{1}$, Decheng Liu', Guohui Mo ${ }^{1}$, Hui Zhang ${ }^{2 *}$ and Yunling Dou ${ }^{* *}$
}

\begin{abstract}
Background: Irritable bowel syndrome (IBS) is the most common functional gastrointestinal disease characterized by chronic abdominal discomfort and pain. The mechanisms of abdominal pain, as a relevant symptom, in IBS are still unclear. We aimed to explore the key genes and neurobiological changes specially involved in abdominal pain in IBS.

Methods: Gene expression data (GSE36701) was downloaded from Gene Expression Omnibus database. Fifty-three rectal mucosa samples from 27 irritable bowel syndrome with diarrhea (IBS-D) patients and 40 samples from 21 healthy volunteers as controls were included. Differentially expressed genes (DEGs) between two groups were identified using the GEO2R online tool. Functional enrichment analysis of DEGs was performed on the DAVID database. Then a protein-protein interaction network was constructed and visualized using STRING database and Cytoscape.

Results: The microarray analysis demonstrated a subset of genes (CCKBR, CCL13, ACPP, BDKRB2, GRPR, SLC1A2, NPFF, $P 2 R X 4, T R P A 1, C C K B R, T L X 2, M R G P R X 3, P A X 2, C X C R 1)$ specially involved in pain transmission. Among these genes, we identified GRPR, NPFF and TRPA1 genes as potential biomarkers for irritating abdominal pain of IBS patients.

Conclusions: Overexpression of certain pain-related genes (GRPR, NPFF and TRPA1) may contribute to chronic visceral hypersensitivity, therefore be partly responsible for recurrent abdominal pain or discomfort in IBS patients. Several synapses modification and biological process of psychological distress may be risk factors of IBS.
\end{abstract}

Keywords: Bioinformatics analysis, Biomarker, Visceral hypersensitivity, Abdominal pain, Irritable bowel syndrome

\section{Background}

Chronic abdominal pain is an important symptom of irritable bowel syndrome (IBS), which affects 3.8-9.2\% of the global population [1]. Recurrent abdominal pain can substantially reduce quality of life in IBS patients and there is no effective and standard treatment currently [2]. In order to identify new therapies, it is important to understand the underlying mechanism of chronic abdominal pain.

\footnotetext{
*Correspondence: zhanghui@gd2h.org.cn; sysdyl@163.com

${ }^{\dagger}$ Zhongyuan Lin and Yimin Wang have contributed equally to this work ${ }^{1}$ Department of Anesthesiology, The First Affiliated Hospital of Sun Yatsen University, Guangzhou 510000, Guangdong, China

2 Department of Anesthesiology, Guangdong Second Provincial General Hospital, Guangzhou 510000, Guangdong, China
}

Abdominal pain in IBS is thought to be secondary to visceral hypersensitivity $(\mathrm{VH})$, which has been described as low thresholds of stimuli perception arising from the gut [3]. Visceral hypersensitivity is characterized by two components: allodynia, a painful response to stimuli that are normally not painful and hyperalgesia, an enhanced response to a painful stimulus [4]. The underlying pathogenesis that lead to $\mathrm{VH}$ in patients who have IBS is not fully understood. However, the prevailing viewpoint in the pathogenesis involves psychosocial factors, subtle inflammation and alteration in the neuronal excitability of gut sensory pathways, which is responsible for transmitting nociceptive information from the periphery to the central nervous system [5]. Specific changes of a variety of receptors and ion channels both in the expression

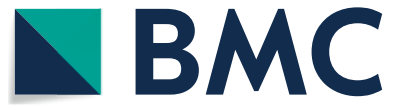

(c) The Author(s) 2021. Open Access This article is licensed under a Creative Commons Attribution 4.0 International License, which permits use, sharing, adaptation, distribution and reproduction in any medium or format, as long as you give appropriate credit to the original author(s) and the source, provide a link to the Creative Commons licence, and indicate if changes were made. The images or other third party material in this article are included in the article's Creative Commons licence, unless indicated otherwise in a credit line to the material. If material is not included in the article's Creative Commons licence and your intended use is not permitted by statutory regulation or exceeds the permitted use, you will need to obtain permission directly from the copyright holder. To view a copy of this licence, visit http://creativecommons.org/licenses/by/4.0/. The Creative Commons Public Domain Dedication waiver (http://creativeco mmons.org/publicdomain/zero/1.0/) applies to the data made available in this article, unless otherwise stated in a credit line to the data. 
and function have been documented in visceral pain conditions relevant to irritable bowel syndrome. Researches have shown genetic factors may play a role in those specific changes in IBS [6]. Beyder and colleagues have reported that a mutation of the SCN5A-encoded voltagegated sodium channel, type V (alpha subunit) was associated with abdominal pain [7]. Other investigators have investigated genetic changes related to enteric infection, epithelial barrier function and immune regulation, serotonin signaling, cannabinoid receptors, and bile acid synthesis, with varying results [8].

Bioinformatics analysis provides tools to produce overviews of genetic networks and potential biological pathways based on large-scale information. This study aimed to explore the molecular mechanisms specially involved in pain transmission underlying IBS and to identify hub genes and potential pathways associated with the pathogenesis of IBS.

\section{Methods}

Microarray data search and selection of eligible data set The microarray data of GSE36701 was downloaded from the GEO database (www.ncbi.nlm.nih.gov/geo/) with its microarray platform as GPL570 (Affymetrix Human Genome U133 Plus 2.0 Array). In this microarray, 53 samples of rectal mucosa from 27 IBS-D patients with obvious abdominal pain were obtained and 40 samples from 21 healthy volunteers as controls. Subjects completed a Talley IBS symptom questionnaire modified to include days with pain. IBS was diagnosed according to the Rome II criteria. Those with IBS also completed IBS quality of life questionnaire and the IBS Symptom Severity Score Questionnaire including severity of visceral pain. Those agreeing to take part underwent sigmoidoscopy without bowel preparation. Two biopsies from each donor were obtained using endoscopic biopsy forceps and the mRNA were extracted for further analysis. After RNA extraction and Microarray processing, samples without visible $18 \mathrm{~S}$ and $28 \mathrm{~S}$ rRNA peaks were excluded. There was one donor in IBS-D group and two donors in HV group only obtained one microarray data. Details of clinical data collection, RNA extraction and microarray processing can be found in GSE36701 dataset citation (https://www.ncbi.nlm.nih.gov/geo/query/acc. cgi?acc $=$ GSE36701).

\section{DEGs'screening}

The expression profiles were expressed as FC (fold change) to produce a normally distributed variable. We screened out DEGs using the online tool GEO2R/R, which was based on limma (Linear Models for Microarray Analysis) R package 3.26.8 (https://www.ncbi.nlm. nih.gov/geo/info/geo2r.html). We applied Benjamini and
Hochberg false discovery rate method for adjustment of the $P$ values. In our study, DEGs between healthy volunteers and IBS-D patients were screened and selected by the cut-off point of $\mathrm{FC} \geq 1.2$ and $P$ value $<0.05$.

\section{Functional enrichment analysis}

The selected DEGs were submitted to the Database for Annotation, Visualization, and Integrated Discovery (DAVID) for further analysis. The DAVID database, version 6.8 Beta (https://david-d.ncifcrf.gov/), offers biological function annotation for researchers [9]. In this study, Gene Ontology (GO) analysis and The Kyoto Encyclopedia of Genes and Genomes (KEGG) pathways of DEGs were obtained from the DAVID database. The biological processes and pathways might contribute to verify the significative DEGs and to IBS treatments. Functional annotation analysis was performed by two-sided hypergeometric test and Benjamini and Hochberg methods was applied for multiple testing correction. Min. Count $\geq 2$ and $P$ value $<0.05$ was chosen as the threshold.

\section{Protein-protein interaction (PPI) analysis}

Then we constructed PPI network of DEGs from Search Tool for the Retrieval of Interacting Genes (STRING, http://string-db.org/) [10]. STRING is a public database of known and predicted protein-protein interactions. In this study, we selected confidence score $>0.4$ as a threshold to construct the PPI network. The combined score is calculated by combining the probabilities from the different evidence channels, including high throughput experimental data and literature, and corrected for the probability of randomly observing an association [11]. Then, the list of PPI pairs was downloaded for further analysis. Module clustering analysis for the network was then performed to identify the potential functional modules in the network, using the Molecular Complex Detection (MCODE 1.6.1) in Cytoscape 3.7.1 plugin [12, 13]. The degree cut-off value to 2 and the node score cut-off to 0.2 were set as criteria in the MCODE process.

\section{Results}

\section{Screening and prioritization for DEGs}

An available Expression profiling data set (GSE36701) in NCBI was selected in this study to identify differentially expressed genes in the comparisons between IBS-D patients and the healthy volunteers. Then the differentially expressed genes were further filtered for functional associations with neurotransmitters/ mediators of pain. Each array was normalized by quantile, and then the DEGs analysis was performed ( $P$ value $<0.05, \mathrm{FC} \geq 1.2$ or $\leq 0.8$ ). Compared with the HVs, we find out 9 upregulated genes (CCKBR, CCL13, $A C P P, B D K R B 2, G R P R, S L C 1 A 2, N P F F, P 2 R X 4$, and 
TRPA1) and 4 downregulated genes (TLX2, MRG$P R X 3, C X C R 1$ and $P A X 2)$ that may have relevance in the initiation and development of visceral pain. The most significant upregulated or downregulated genes specially linked to pain transmission are illustrated in Tables 1 and 2.

\section{Functional enrichment analysis}

Functional analysis was carried out with GO biological process and KEGG pathways. Genes differentially were classified according to their putative Gene Ontology (GO) based on similarity with known genes recorded in public databases (Fig. 1). To further understand the functions of the DEGs, we represented significant pathways based on KEGG databases (Fig. 2). The upregulated DEGs were mainly associated with Glutamatergic synapse, Dilated cardiomyopathy, Arginine biosynthesis. The downregulated DEGs were linked to Circadian entrainment, Alcoholism, Aldosterone-regulated sodium reabsorption, Maturity onset diabetes of the young, cGMP-PKG signaling pathway, Dopaminergic synapse, Morphine addiction, Systemic lupus erythematosus, Glutamatergic synapse, Glycine, serine and threonine metabolism, Retrograde endocannabinoid signaling, Renin secretion.

\section{PPI network}

A PPI network of the proteins encoded by identified DEGs was constructed by STRING. To identify the key modules of the PPI network, module clustering was then performed through the MCODE plugin of Cytoscape (Fig. 3). The modules showed that several pain or itch related genes like GRPR, NPFF, CCKBR, BDKRB2, CXCR1 and CCL13 genes (Red Rectangle, Fig. 3) were also clustered and most of these genes also occurred in GO terms or KEGG pathways enriched above. Finally, we identified that GRPR, NPFF and TRPA1 as potential biomarkers for abdominal pain of IBS patients.

\section{Discussion}

Persistent hypersensitivity of sensory pathways innervating the colon is regarded as primary mechanism contributing to the initiation, development, and maintenance of chronic discomfort and abdominal pain in IBS patients $(15,16,39)$. Therefore, determining the mechanisms contributing to these processes is crucial. Swan et al. originally submitted the GSE36701 dataset, performed mRNA expression profiling study of rectal biopsies from donors with healthy volunteers and IBS-D patients [14]. They collected detailed clinical data (including abdominal pain frequency, anxiety and depression scale), using a combination of bioinformatics and experimental approaches to identify candidate genetic polymorphisms in the

Table 1 Upregulated genes specially involved in pain transmission in IBS-D patients in comparison with HVs

\begin{tabular}{|c|c|c|c|c|}
\hline ID & $P$ value & Gene symbol & Gene title & FC \\
\hline 206407_s_at & $1.98 \mathrm{E}-04$ & CCL13 & C-C motif chemokine ligand 13 & 1.58 \\
\hline 205870_at & $1.51 \mathrm{E}-03$ & BDKRB2 & Bradykinin receptor B2 & 1.38 \\
\hline 217590_s_at & $1.62 \mathrm{E}-02$ & TRPA1 & $\begin{array}{l}\text { Transient receptor potential cation channel subfamily A } \\
\text { member } 1\end{array}$ & 1.23 \\
\hline 204393_s_at & $4.26 \mathrm{E}-03$ & ACPP & Acid phosphatase, prostate & 1.55 \\
\hline 208389_s_at & $1.11 \mathrm{E}-02$ & SLC1A2 & Solute carrier family 1 member 2 & 1.31 \\
\hline 204088_at & $1.41 \mathrm{E}-02$ & P2RX4 & Purinergic receptor $\mathrm{P} 2 \mathrm{X} 4$ & 1.23 \\
\hline 207929_at & $2.62 \mathrm{E}-02$ & GRPR & Gastrin releasing peptide receptor & 1.37 \\
\hline 206402_s_at & 4.65E-02 & NPFF & Neuropeptide FF-amide peptide precursor & 1.25 \\
\hline 234475_x_at & $1.70 \mathrm{E}-02$ & CCKBR & Cholecystokinin B receptor & 1.77 \\
\hline
\end{tabular}

$H V$ s healthy volunteers, $F C$ fold change

Table 2 Downregulated genes specially involved in pain transmission in IBS-D patients in comparison with HV

\begin{tabular}{lllll}
\hline ID & P value & Gene symbol & Gene title & FC \\
\hline 207410_s_at & $2.27 \mathrm{E}-02$ & TLX2 & T-cell leukemia homeobox 2 & 0.65 \\
1553293_at & $1.24 \mathrm{E}-02$ & MRGPRX3 & MAS related GPR family member X3 \\
206228_at & $2.58 \mathrm{E}-02$ & PAX2 & Paired box 2 & 0.71 \\
207094_at & $7.11 \mathrm{E}-03$ & CXCR1 & C-X-C motif chemokine receptor 1 & 0.76 \\
\hline
\end{tabular}

HVs healthy volunteers, FC fold change 


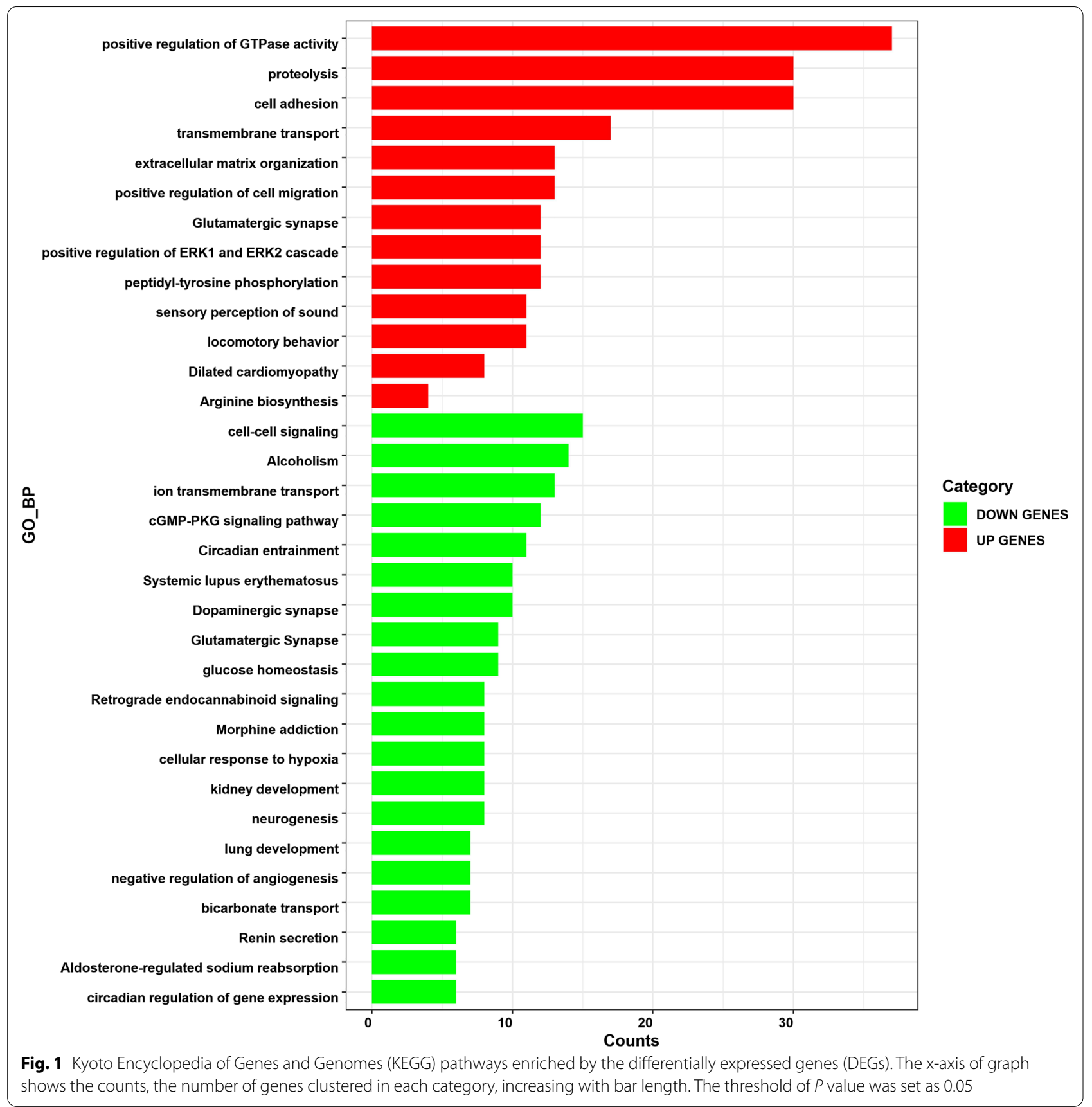

IBS [14]. While we further filtered for functional associations related to neurotransmitters/mediators of pain. Most notable among those genes were shown in Table 1 (upregulated genes) and Table 2 (downregulated genes). Interestingly, GRPR, NPFF, TRPA1, BDKRB2, MRGPRX3, that commonly regarded as factor also regulating itch signaling pathways were found [15-17]. Finally, three genes including GRPR, NPFF and TRPA1 were considered to play an essential role in abdominal pain in IBS.
In the colon, afferent sensitization occurs via a variety of processes [18], including histamine-dependent mechanisms and histamine-independent mechanisms $[19,20]$; Evidence have been accumulated that activation of receptors associated with the above two itch pathways on colon-innervating afferents induces visceral hypersensitivity $[19,21]$. Gastrin-releasing peptide receptor expressing (GRPR)+ neurons have a central role in the spinal transmission of both histaminergic and 


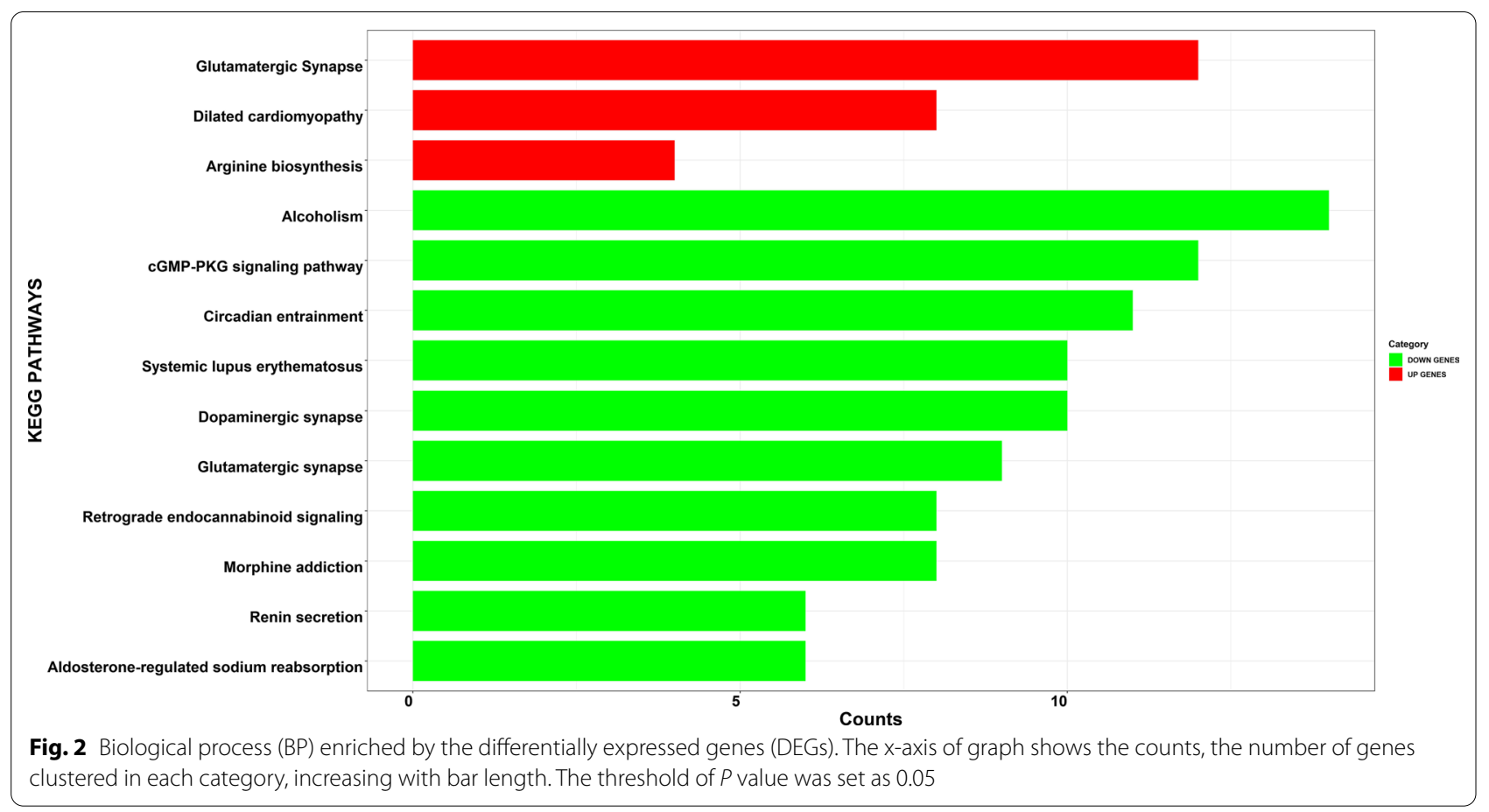

non-histaminergic itch [22]. In our study, GRPR was significantly upregulated in IBS-D patients and identified as a hub gene by MCODE. GRPR is a G protein-coupled receptor and mediates itch sensation mainly via the PI3K $\gamma /$ Akt pathway [23]. At the same time, GRP induces neutrophil chemotaxis through GRPR via p38, ERK1/2 [24] and PI3K activation and p38, ERK and PI3K are important mediators in visceral pain [25-27]. Itch and pain signals are conveyed by distinct yet interacting neuronal pathways: pruritogens at higher doses produce pain to suppress itch [28, 29]; the frequency of abdominal pain in IBS was higher in patients with chronic pruritus than in healthy controls [30]. In addition, Neuropeptide FF $(N P F F)$, the histamine-independent itch receptors agonist, evoking colonic afferent mechanical hypersensitivity $[17,19]$, was also clustered by Cytoscape module in our study. Therefore, we speculated that altered GRP-GRPR signaling and NPFF in spinal dorsal horn participate in visceral hypersensitivity through sensitization of itch transmission neurons, thereby contributing to abdominal pain or discomfort.

In the present study, another gene related to pain transmission deserve attention. Our results, together with previous studies have indicated significantly upregulated TRPA1 (Transient receptor potential ankyrin 1) mRNA expression in biopsies of IBS patients [31]. TRPA1 has been implicated in mechanical hypersensitivity of colonic afferents and both bradykinin and TNF- $\alpha$ induce visceral hypersensitivity through a
TRPA1-dependent mechanism [32]. On the other hand, TRPA1 can also induce the inflammatory response via neurogenic inflammation: activation and sensitization of TRPA1 and release of substance P contribute to the initiation and development of colitis in mice, which correspondingly re-sensitises nociceptors [33]. TRPA1 expressed by intestinal enterochromaffin cells can serves as the primary detector of intestinal irritants prior to direct sub-mucosal damage [34]. These findings further highlight TRPA1 as an important integrator of sensory signals in colonic afferents by inducing mechanical visceral hypersensitivity.

As we known, IBS is a multifactorial disease. Abnormal stress response, psychological distress and infectious or inflammatory response in susceptible population may initiate visceral hypersensitivity that results in the development of IBS symptoms. According to the functional enrichment analyses, two pathways were associated with dysregulation of renin-angiotensin system (RAS), which is a potent target of stress-induced intestinal inflammation in a murine model of IBS [35]. Circadian entrainment and disorder of several synapses such as Glutamatergic synapse, Dopaminergic synapse may be risk factors of IBS. Besides, certain pathways directly involved in pain transmission were enriched, including Morphine addiction and Retrograde endocannabinoid signaling. Endocannabinoids are involved in controlling motility, secretion and intestinal inflammation [36]. The endocannabinoid system in DRG neurons mediate 


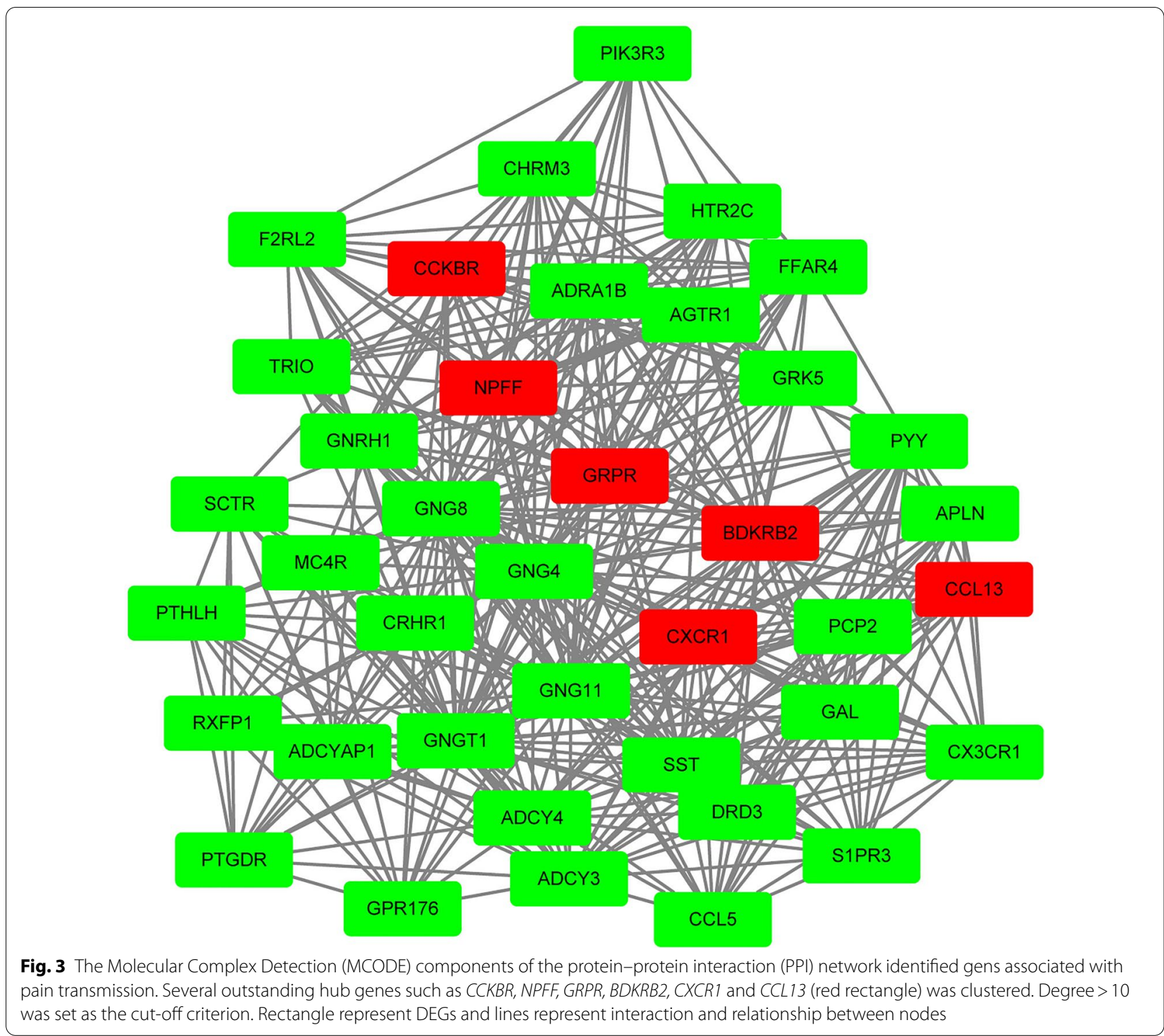

stress-induced visceral hypersensitivity in a mouse model of IBS [37].

\section{Conclusions}

Our results showed that GRPR, NPFF and TRPA1 genes may be potential biomarkers for the diagnosis and new targets for treatment of abdominal pain in IBS. Several synapses modification and biological process of psychological distress may be risk factors of IBS. However, further studies are required to confirm the clinical significance of these findings.

\section{Abbreviations}

IBS: Irritable bowel syndrome; HV: Healthy volunteer; GRPR: Gastrin-releasing peptide receptor; VH: Visceral hypersensitivity; TRPA1: Transient receptor potential ankyrin 1; NPFF: Neuropeptide FF; GEO: Gene expression omnibus;
DEGs: Differentially expressed genes; IBS-D: Irritable bowel syndrome with diarrhea; DAVID: Database for annotation, visualization, and integrated discovery; STRING: Search tool for the retrieval of interacting genes; GO: Gene ontology; KEGG: Kyoto encyclopedia of genes and genomes; PPI: Protein-protein interaction; MCODE: Molecular complex detection; CXCL13: C-X-C motif chemokine ligand 13; CXCR1: C-X-C motif chemokine receptor 1.

\section{Acknowledgements}

Not applicable.

\section{Authors' contributions}

ZYL and YMW contributed to this work equally. ZYL: data collection and writing up of the first draft of the paper; YMW: data analysis. SQL, DCL and GHM did literature research and analysis of the data. Correspondence and requests for materials should be addressed to YLD and HZ: study design and modifying paper. All authors have read and approved the manuscript and ensure that this is the case.

\section{Funding}

No funding. 


\section{Availability of data and materials}

The raw data of microarray experiment (its accession numbers are GSE36701) was downloaded from the Gene Expression omnibus (GEO) repository (https ://www.ncbi.nlm.nih.gov/geo/). All data are publicly accessible. All data generated or analyzed during this study are included in this published article.

\section{Ethics approval and consent to participate}

Ethical approval is not required because this analysis was performed on public database. The original research ethics information can be accessed in GEO database (https://www.ncbi.nlm.nih.gov/geo/).

\section{Consent for publication}

Not applicable.

\section{Competing interests}

The authors declare that they have no competing interests.

Received: 1 June 2020 Accepted: 25 January 2021

Published online: 02 February 2021

\section{References}

1. Oka P, Parr H, Barberio B, Black CJ, Savarino EV, Ford AC. Global prevalence of irritable bowel syndrome according to Rome III or IV criteria: a systematic review and meta-analysis. Lancet Gastroenterol Hepatol. 2020;5(10):908-17.

2. Chey WD, Kurlander J, Eswaran S. Irritable bowel syndrome: a clinical review. JAMA. 2015;313(9):949-58.

3. Pichetshote N, Pimentel M. An approach to the patient with chronic undiagnosed abdominal pain. Am J Gastroenterol. 2019;114(5):726-32.

4. Ceuleers $H$, Van Spaendonk $H$, Hanning N, Heirbaut J, Lambeir AM, Joossens J, Augustyns K, De Man JG, De Meester I, De Winter BY. Visceral hypersensitivity in inflammatory bowel diseases and irritable bowel syndrome: the role of proteases. World J Gastroenterol. 2016;22(47):10275-86.

5. Enck P, Aziz Q, Barbara G, Farmer AD, Fukudo S, Mayer EA, Niesler B, Quigley EM, Rajilić-Stojanović M, Schemann M, et al. Irritable bowel syndrome. Nat Rev Dis Primers. 2016;2:16014.

6. Distrutti E, Cipriani S, Mencarelli A, Renga B, Fiorucci S. Probiotics VSL\#3 protect against development of visceral pain in murine model of irritable bowel syndrome. PLoS ONE. 2013;8(5):e63893.

7. Beyder A, Mazzone A, Strege PR, Tester DJ, Saito YA, Bernard CE, Enders FT, Ek WE, Schmidt PT, Dlugosz A, et al. Loss-of-function of the voltage-gated sodium channel NaV1.5 (channelopathies) in patients with irritable bowel syndrome. Gastroenterology. 2014;146(7):1659-68.

8. Holtmann GJ, Ford AC, Talley NJ. Pathophysiology of irritable bowel syndrome. Lancet Gastroenterol Hepatol. 2016;1(2):133-46.

9. da Huang W, Sherman BT, Lempicki RA. Systematic and integrative analysis of large gene lists using DAVID bioinformatics resources. Nat Protoc. 2009:4(1):44-57.

10. Szklarczyk D, Franceschini A, Kuhn M, Simonovic M, Roth A, Minguez $P$, Doerks T, Stark M, Muller J, Bork P, et al. The STRING database in 2011: functional interaction networks of proteins, globally integrated and scored. Nucleic Acids Res. 2011:39(Database issue):D561-8.

11. von Mering C, Jensen LJ, Snel B, Hooper SD, Krupp M, Foglierini M, Jouffre N, Huynen MA, Bork P. STRING: known and predicted protein-protein associations, integrated and transferred across organisms. Nucleic Acids Res. 2005;33(Database issue):D433-7.

12. Saito R, Smoot ME, Ono K, Ruscheinski J, Wang PL, Lotia S, Pico AR, Bader GD, Ideker T. A travel guide to Cytoscape plugins. Nat Methods. 2012;9(11):1069-76.

13. Wang J, Zhong J, Chen G, Li M, Wu FX, Pan Y. ClusterViz: a cytoscape APP for cluster analysis of biological network. IEEE/ACM Trans Comput Biol Bioinform. 2015;12(4):815-22.

14. Swan C, Duroudier NP, Campbell E, Zaitoun A, Hastings M, Dukes GE, Cox J, Kelly FM, Wilde J, Lennon MG, et al. Identifying and testing candidate genetic polymorphisms in the irritable bowel syndrome (IBS): association with TNFSF15 and TNFalpha. Gut. 2013;62(7):985-94.

15. Mishra SK, Hoon MA. The cells and circuitry for itch responses in mice. Science. 2013;340(6135):968-71.
16. LaMotte $\mathrm{RH}$, Dong $X$, Ringkamp M. Sensory neurons and circuits mediating itch. Nat Rev Neurosci. 2014;15(1):19-31.

17. Gutierrez-Mecinas M, Bell A, Polgar E, Watanabe M, Todd AJ. Expression of neuropeptide FF defines a population of excitatory interneurons in the superficial dorsal horn of the mouse spinal cord that respond to noxious and pruritic stimuli. Neuroscience. 2019;416:281-93.

18. Sadeghi M, Erickson A, Castro J, Deiteren A, Harrington AM, Grundy L Adams DJ, Brierley SM. Contribution of membrane receptor signalling to chronic visceral pain. Int J Biochem Cell Biol. 2018;98:10-23.

19. Castro J, Harrington AM, Lieu T, Garcia-Caraballo S, Maddern J, Schober G, O'Donnell T, Grundy L, Lumsden AL, Miller P, et al. Activation of pruritogenic TGR5, MrgprA3, and MrgprC11 on colon-innervating afferents induces visceral hypersensitivity. JCI Insight. 2019;4(20):e131712.

20. Wouters MM, Balemans D, Van Wanrooy S, Dooley J, Cibert-Goton V, Alpizar YA, Valdez-Morales EE, Nasser Y, Van Veldhoven PP, Vanbrabant W, et al. Histamine receptor H1-mediated sensitization of TRPV1 mediates visceral hypersensitivity and symptoms in patients with irritable bowel syndrome. Gastroenterology. 2016;150(4):875-887.e879.

21. Van Remoortel S, Ceuleers H, Arora R, Van Nassauw L, De Man JG, Buckinx R, De Winter BY, Timmermans JP. Mas-related G protein-coupled receptor $C 11$ (Mrgprc11) induces visceral hypersensitivity in the mouse colon: a novel target in gut nociception? Neurogastroenterol Motil. 2019;31(8):e13623.

22. Kiguchi N, Uta D, Ding H, Uchida H, Saika F, Matsuzaki S, Fukazawa Y, Abe M, Sakimura K, Ko MC, et al. GRP receptor and AMPA receptor cooperatively regulate itch-responsive neurons in the spinal dorsal horn. Neuropharmacology. 2020;170:108025.

23. Pereira PJ, Machado GD, Danesi GM, Canevese FF, Reddy VB, Pereira TC, Bogo MR, Cheng YC, Laedermann C, Talbot S, et al. GRPR/PI3Kgamma: partners in central transmission of itch. J Neurosci. 2015;35(49):16272-81.

24. Czepielewski RS, Porto BN, Rizzo LB, Roesler R, Abujamra AL, Pinto LG, Schwartsmann G, Cunha Fde Q, Bonorino C. Gastrin-releasing peptide receptor (GRPR) mediates chemotaxis in neutrophils. Proc Natl Acad Sci USA. 2012;109(2):547-52.

25. Luo C, Zhang YL, Luo W, Zhou FH, Li CQ, Xu JM, Dai RP. Differential effects of general anesthetics on anxiety-like behavior in formalin-induced pain: involvement of ERK activation in the anterior cingulate cortex. Psychopharmacology. 2015;232(24):4433-44.

26. Chen Z, Xie F, Bao M, Li X, Chao Y, Lin C, Guo R, Zhang C, Wu A, Yue Y, et al. Activation of p38 MAPK in the rostral ventromedial medulla by visceral noxious inputs transmitted via the dorsal columns may contribute to pelvic organ cross-sensitization in rats with endometriosis. Neuroscience. 2015;291:272-8.

27. Shen S, Al-Thumairy HW, Hashmi F, Qiao LY. Regulation of transient receptor potential cation channel subfamily $\mathrm{V} 1$ protein synthesis by the phosphoinositide 3-kinase/Akt pathway in colonic hypersensitivity. Exp Neurol. 2017:295:104-15.

28. Liu T, Ji RR. New insights into the mechanisms of itch: are pain and itch controlled by distinct mechanisms? Pflugers Arch. 2013;465(12):1671-85.

29. Sun YG, Zhao ZQ, Meng XL, Yin J, Liu XY, Chen ZF. Cellular basis of itch sensation. Science. 2009;325(5947):1531-4.

30. Ekiz O, Balta I, Ozuguz P, Sen BB, Rifaioglu EN, Ekiz F, Yuksel I, Coban S, Basar O. Irritable bowel syndrome in patients with chronic pruritus of undetermined origin. J Eur Acad Dermatol Venereol. 2014;28(8):1034-9.

31. Brierley SM, Hughes PA, Page AJ, Kwan KY, Martin CM, O'Donnell TA, Cooper NJ, Harrington AM, Adam B, Liebregts T, et al. The ion channel TRPA 1 is required for normal mechanosensation and is modulated by algesic stimuli. Gastroenterology. 2009;137(6):2084-2095.e2083.

32. Hughes PA, Harrington AM, Castro J, Liebregts T, Adam B, Grasby DJ, Isaacs NJ, Maldeniya L, Martin CM, Persson J, et al. Sensory neuro-immune interactions differ between irritable bowel syndrome subtypes. Gut. 2013;62(10):1456-65.

33. Engel MA, Leffler A, Niedermirtl F, Babes A, Zimmermann K, Filipovic MR, Izydorczyk I, Eberhardt M, Kichko TI, Mueller-Tribbensee SM, et al. TRPA 1 and substance P mediate colitis in mice. Gastroenterology. 2011;141(4):1346-58.

34. Bellono NW, Bayrer JR, Leitch DB, Castro J, Zhang C, O'Donnell TA, Brierley SM, Ingraham HA, Julius D. Enterochromaffin cells are gut chemosensors that couple to sensory neural pathways. Cell. 2017;170(1):185-198.e116.

35. Yisireyili M, Uchida Y, Yamamoto K, Nakayama T, Cheng XW, Matsushita T, Nakamura S, Murohara T, Takeshita K. Angiotensin receptor blocker 
irbesartan reduces stress-induced intestinal inflammation via AT1a signaling and ACE2-dependent mechanism in mice. Brain Behav Immun. 2018;69:167-79.

36. Duncan M, Davison JS, Sharkey KA. Review article: endocannabinoids and their receptors in the enteric nervous system. Aliment Pharmacol Ther. 2005;22(8):667-83.

37. Hughes PA, Brierley SM, Martin CM, Brookes SJ, Linden DR, Blackshaw LA. Post-inflammatory colonic afferent sensitisation: different subtypes, different pathways and different time courses. Gut. 2009;58(10):1333-41.

\section{Publisher's Note}

Springer Nature remains neutral with regard to jurisdictional claims in published maps and institutional affiliations.
Ready to submit your research? Choose BMC and benefit from:

- fast, convenient online submission

- thorough peer review by experienced researchers in your field

- rapid publication on acceptance

- support for research data, including large and complex data types

- gold Open Access which fosters wider collaboration and increased citations

- maximum visibility for your research: over 100M website views per year

At BMC, research is always in progress.

Learn more biomedcentral.com/submissions 